V.P. VELESCHUK, O.I. VLASENKO, Z.K. VLASENKO, V.A. GNATYUK, S.N. LEVYTSKYI

V.E. Lashkaryov Institute of Semiconductor Physics, National Academy of Sciences of Ukraine (41, Nauky Ave., Kyiv 03028, Ukraine; e-mail: vvvit@ukr.net)

\title{
DEPENDENCE OF THE CdTe MELTING THRESHOLD ON THE PULSE DURATION AND WAVELENGTH OF LASER RADIATION AND THE PARAMETERS OF NON-EQUILIBRIUM CHARGE CARRIERS
}

PACS 81.15.Fg, 81.65.Cf,

\begin{abstract}
The dependences of the melting threshold of CdTe under the pulsed laser irradiation on the radiation wavelength $\lambda$ and the laser pulse duration $\tau_{\mathrm{p}}$ are calculated with regard for the nonequilibrium character of charge carriers. Three components of the energy released at the thermalization of excited carriers under the nanosecond laser irradiation of CdTe in the fundamental absorption region are considered: the component that dominates immediately after the excitation, and the components released at the nonradiative bulk and nonradiative surface recombinations. Together, they determine the depth of heat penetration into the crystal and, therefore, its melting threshold. It is shown that the CdTe melting threshold grows from 2.6 to $4.75 \mathrm{MW} / \mathrm{cm}^{2}$, when $\lambda$ changes from 300 to $800 \mathrm{~nm}$ at $\tau_{\mathrm{p}}=20 \mathrm{~ns}$. The changes in the nonequilibrium charge carrier parameters (the surface recombination rate, lifetime, and diffusion depth) are found to vary the CdTe melting threshold by at least 30\%.

Ke ywords: cadmium telluride, pulsed laser irradiation.
\end{abstract}

\section{Introduction}

Cadmium telluride is a base material for the creation of detectors of x-rays and gamma radiation, as well as infrared sensors. Special attention to CdTe is associated, in particular, with large atomic numbers of its constituting elements and a considerable transverse cross-section for the photo-electric absorption [1-5].

In the formation of CdTe-based barrier structures to detect gamma radiation, one of the effective methods to treat the surface is the application of a nanosecond laser irradiation. In some cases, it allows the required parameters of the surface state to be optimized at the stage of technological treatments, when contacts $(\mathrm{Ag}, \mathrm{In}, \mathrm{Au})$ are deposited and a barrier is formed [2-4]. A challenging problem also concerns the formation of ordered nanostructures on the CdTe surface under a pulsed laser irradiation (PLI) [6].

For the PLI of semiconductors and semiconductorbased structures, the laser radiation with various

(C) V.P. VELESCHUK, O.I. VLASENKO, Z.K. VLASENKO, V.A. GNATYUK,

S.N. LEVYTSKYI, 2017

ISSN 2071-0194. Ukr. J. Phys. 2017. Vol. 62, No. 2 pulse durations $\tau_{\mathrm{p}}$ and various radiation wavelength $\tau_{\mathrm{p}}$ is used. Ruby $(\lambda=694 \mathrm{~nm})$ and neodymium (the first, $\lambda=1064 \mathrm{~nm}$, and second, $\lambda=532 \mathrm{~nm}$, harmonics) lasers, as well as excimer $\operatorname{KrF}(\lambda=248 \mathrm{~nm})$ and $\mathrm{XeF}(\lambda=351 \mathrm{~nm})$ ones, are mainly applied to modify the surface. Typical values of the parameter $\tau_{\mathrm{p}}$ for them are 7, 20, 80, $120 \mathrm{~ns}$, and others. Therefore, in this work, we are interested first of all in the pulse duration interval $\tau_{\mathrm{p}}=5 \div 120 \mathrm{~ns}$.

While solving the problems of this kind, it is often required to know-or at least to estimate in advancethe melting temperature and the melting threshold $I_{\mathrm{th}}$ of a CdTe surface subjected to PLI, and their dependences on the laser pulse duration $\tau_{\mathrm{p}}$, radiation wavelength (the optical absorption coefficient $\alpha(\lambda)$ ), and electrophysical parameters of the CdTe surface, in particular, the surface recombination rate $S$ and the lifetime of nonequilibrium charge carriers (NECs). Those parameters depend on the surface treatment procedure [7] and the concentration of doping impurities. Relevant experimental researches are very labor- and time-consuming. Therefore, the theoretical calculation of $I_{\mathrm{th}}$ and the surface temperature 
as functions of $\tau_{\mathrm{p}}, \alpha(\lambda)$, and other parameters becomes very useful.

The literature sources contain mismatches concerning the values of CdTe melting threshold and, accordingly, various interpretations of changes in the photo-electric properties under a nanosecond laser irradiation, provided identical experimental conditions. For example, in works [8,9], the melting threshold for the $\mathrm{CdTe}(111)$ face under the irradiation using a ruby laser with $\tau_{\mathrm{p}}=20 \mathrm{~ns}$ was experimentally and theoretically found to equal $2 \mathrm{MW} / \mathrm{cm}^{2}$ $\left(40 \mathrm{~mJ} / \mathrm{cm}^{2}\right)$. Under the same conditions for the CdTe (111) surface, $I_{\mathrm{th}}=8 \mathrm{MW} / \mathrm{cm}^{2}$ in our work [10], $4 \mathrm{MW} / \mathrm{cm}^{2}$ in work [11], and 10-12 $\mathrm{MW} / \mathrm{cm}^{2}$ in work [12]. In researches [13-15] carried out for $\mathrm{CdTe}(111), I_{\mathrm{th}}$ was evaluated to equal $300 \mathrm{~mJ} / \mathrm{cm}^{2}$ $\left(15 \mathrm{MW} / \mathrm{cm}^{2}\right)$. Under the irradiation with an excimer $\mathrm{KrF}$ laser $\left(\lambda=248 \mathrm{~nm}, \tau_{\mathrm{p}}=20 \mathrm{~ns}\right), I_{\mathrm{th}}=$ $=2.5 \mathrm{MW} / \mathrm{cm}^{2}[3,4,16]$.

\section{Calculation Formulas for the Melting Threshold}

Certainly, the rapid (tens or hundreds of nanoseconds) process of heating-cooling of the CdTe surface under a nanosecond laser irradiation is rather complicated for a mathematical description with regard for the temperature dependences of the thermal parameters and the concentration of photoexcited NECs. The threshold value for the laserinduced melting of the crystal surface is determined first of all by the heat diffusion depth $L_{\mathrm{H}}=\sqrt{k \tau_{\mathrm{p}}}$ and the light absorption depth $d \sim \alpha^{-1}$, where $\alpha$ is the absorption coefficient, and $k$ the thermal diffusivity coefficient. The melting threshold for a semiconductor surface under PLI is theoretically determined, as a rule, by solving a non-stationary equation of thermal conductivity with a corresponding boundary condition across the phase interface (the Stefan problem).

The mathematical modeling of phase transitions initiated in cadmium telluride by a pulsed laser radiation on the basis of the heat conductivity equation $[4,11,16,17]$ is complicated due to the account for those parts of the optical radiation energy that are spent on the instant thermalization $\left(\tau \approx 10^{-12} \mathrm{~s}\right)$ and the excitation of the electron-hole plasma followed by its diffusion and recombination. In work [18], this was done by making allowance for the energy components that are released at the thermalization of excited charge carriers immediately after their excitation and at the nonradiative bulk and surface recombinations. Taken together, those components determine the depth of heat penetration into the crystal and, accordingly, the melting threshold. In other words, it is the "semiconductor" crystal parameters that are taken into consideration. Therefore, the theoretical calculation of the laser-induced heating process should provide a detailed account for the optical parameters, the NEC and heat diffusion coefficients, and the variation of those parameters with the NEC concentration and the temperature. In the case of uniform irradiation of the surface of a semiinfinite crystal, the power density $I$ that is required to heat up the surface from the initial temperature $T_{0}$ to the final temperature $T_{f}$ is described by the following well-known formula (see, e.g. works $[18,19]$ ):

$I_{0}=\frac{\rho c_{\mathrm{P}}\left(T_{0}\right) \Delta T L_{\mathrm{H}}}{\left[1-R\left(T_{0}\right)\right] \tau_{\mathrm{p}}}$,

where $\rho$ is the density, $c_{\mathrm{P}}$ the specific heat, $R$ the optical reflectance, $\tau_{\mathrm{p}}$ the laser pulse duration, and $\Delta T=T_{f}-T_{0}$. Unlike the simple expression $L_{\mathrm{H}} \sim$ $\sim \sqrt{k \tau_{\mathrm{p}}}$, the depth of heat penetration into a material in formula (1) is given by the following expression, in which the NEC parameters have already been taken into account [18]:

$L_{\mathrm{H}}=\frac{1-R\left(T_{0}\right)}{c_{\mathrm{P}}\left(T_{0}\right) \Delta T} \int_{T_{0}}^{T_{f}} \frac{d T c_{\mathrm{P}}}{(1-R) \alpha}\left[\chi_{\mathrm{T}} /\left(L_{\mathrm{T}} \alpha+1\right)+\right.$

$\left.+\chi_{\mathrm{B}}^{\mathrm{NR}}\left(L_{\mathrm{T}} \alpha+L_{\mathrm{D}} \alpha+1\right)+\chi_{\mathrm{S}}^{\mathrm{NR}} /\left(L_{\mathrm{T}} \alpha\right)\right]^{-1}$,

where $\alpha=\alpha_{1}+\alpha_{2}+\alpha_{\mathrm{FC}}$ is the coefficient of total optical absorption; $\alpha_{1}$ and $\alpha_{2}$ are the coefficients of one- and two-photon, respectively, interband absorption; $\alpha_{F C}$ the absorption coefficient for free charge carriers; $L_{\mathrm{D}}=\left(D \tau_{\mathrm{B}}\right)^{1 / 2}$ is the diffusion depth for free charge carriers;

$D=\frac{k_{\mathrm{B}} T}{e} \frac{\mu_{\mathrm{n}} \mu_{\mathrm{p}}}{\mu_{\mathrm{n}}+\mu_{\mathrm{p}}}$

is the coefficient of ambipolar diffusion for charge carriers; $k_{\mathrm{B}}$ the Boltzmann constant; $\tau_{\mathrm{B}}$ the lifetime of charge carriers at their recombination in the crystal bulk; $\mu_{n}$ and $\mu_{\mathrm{p}}$ are the mobilities of electrons and holes, respectively; and

$L_{\mathrm{T}}(T) \approx \pi^{1 / 2}\left[k(T) \tau_{\mathrm{p}}\right]^{1 / 2}\left(T-T_{0}\right) / \Delta T$.

ISSN 2071-0194. Ukr. J. Phys. 2017. Vol. 62, No. 2 
The parameters $\chi_{\mathrm{T}}, \chi_{\mathrm{B}}^{\mathrm{NR}}$, and $\chi_{\mathrm{S}}^{\mathrm{NR}}$ mean those components of the laser radiation energy that are released at the thermalization of excited charge carriers immediately after their excitation at nonradiative bulk and surface recombinations, respectively:

$\chi_{\mathrm{T}}=\left\{\left[1-\frac{\eta_{Q} E_{\mathrm{R}}}{h \nu}\right] \alpha_{1}+\left[1-\left(\frac{E_{\mathrm{R}}}{2 h \nu}\right)\right] \alpha_{2}+\alpha_{\mathrm{FC}}\right\} / \alpha$,

$\chi_{\mathrm{B}}^{\mathrm{NR}}=\left(\tau / \tau_{\mathrm{B}}^{\mathrm{NR}}\right)\left(1-\chi_{\mathrm{T}}\right)$,

$\chi_{\mathrm{S}}^{\mathrm{NR}}=\left(\tau / \tau_{\mathrm{S}}^{\mathrm{NR}}\right)\left(1-\chi_{\mathrm{T}}\right) L_{\mathrm{D}} \alpha /\left(L_{\mathrm{D}} \alpha+1\right)$,

where $\eta_{Q}$ is a dimensionless parameter equal to the ratio between the photon energy that is thermalized at the absorption depth $1 / \alpha$ and the energy of NEC recombination at the diffusion depth, $h \nu$ is the energy of a photon, $E_{\mathrm{R}}$ the recombination energy, $\tau=\left(\tau_{\mathrm{B}}^{-1}+\tau_{\mathrm{S}}^{-1}\right)^{-1}$ is the effective time of charge carrier recombination, $\tau_{S}=L_{\mathrm{D}} / S$ is the effective lifetime of NECs at the surface, $S$ the surface recombination rate, and $\tau_{\mathrm{B}}^{\mathrm{NR}}$ and $\tau_{\mathrm{S}}^{\mathrm{NR}}$ are the lifetimes of NECs at their nonradiative recombination in the bulk and at the surface, respectively.

\section{Results and Their Discussion}

In expressions (1)-(5), the temperature dependences of thermal quantities and NEC parameters have to be taken into account. The corresponding data for CdTe are presented in Table, and the dependences $\alpha(\lambda)$ and $R(\lambda)$ are shown in Fig. 1. The temperature dependence of the absorption coefficient arises due to the presence of charge carriers at the surface and is described rather well by the approximation formula $\alpha(\lambda)=\alpha_{0}+A(\lambda) T$. In particular, at $\lambda=694 \mathrm{~nm}$, we have $\alpha=\left(3 \times 10^{6}+8400 T\right) \mathrm{m}^{-1}$. Despite an insignificant two-photon absorption in the interval of fundamental absorption, this dependence will be used below while making calculations in a wavelength interval of 300-800 $\mathrm{nm}$. In a vicinity of the melting temperature, the parameter $\alpha$ becomes approximately 2.5 times as large. We also have to take into consideration the temporal dependence of the reflectance $R$ : according to the results of work [20], this parameter changes from 0.28 to 0.36 , when $I$ varies from 0 to $0.2 \mathrm{~J} / \mathrm{cm}^{2}$, owing to the start of the melting. In general, the value of $R$ affects the magnitude of $I_{t h}$ rather substantially.

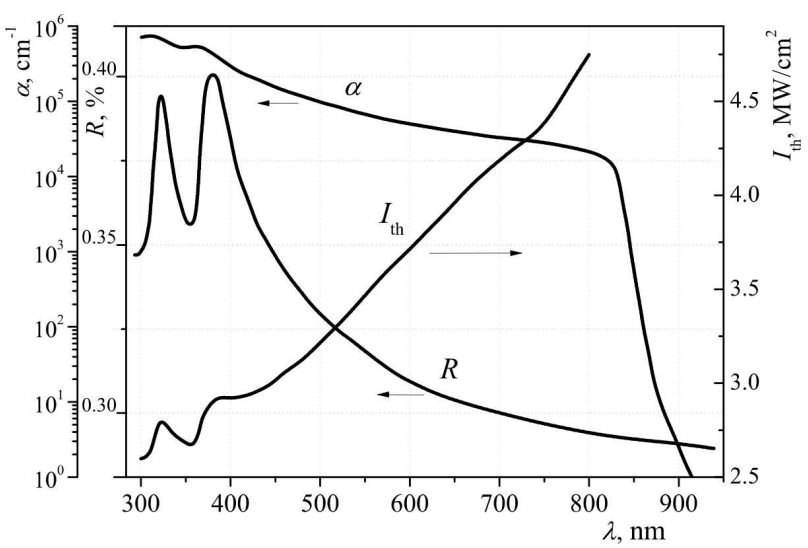

Fig. 1. Calculated dependence of the melting threshold on the laser wavelength, $I_{\mathrm{th}}(\lambda)$, at $\tau_{\mathrm{p}}=20 \mathrm{~ns}$ and experimental dependences $R(\lambda)$ and $\alpha(\lambda)$ for CdTe $[22,24]$

It is important to know the NEC lifetime at the surface and in the bulk of CdTe under PLI. In the general case, the NEC lifetime in the CdTe bulk is given by the expression

$1 / \tau_{\mathrm{B}}=1 / \tau_{\mathrm{SR}}+1 / \tau_{\mathrm{Rad}}+1 / \tau_{\mathrm{Aug}}$,

where $\tau_{\mathrm{SR}}, \tau_{\mathrm{Rad}}$, and $\tau_{\mathrm{Aug}}$ are the lifetimes of charge carrier recombination driven by the Shockley-Read, radiative, and Auger mechanisms, respectively. At high levels of NEC excitation, which takes place at our laser power densities, the Auger recombination [4] dominates. Accordingly, the charge carriers lifetime $\tau_{\mathrm{B}} \approx \tau_{\text {Aug }}=1 / \gamma_{\text {Aug }} n^{2}$, where $n$ is the NEC concentration. On the other hand, the lifetime can be divided into the radiative and nonradiative components, as in expressions (3)-(5):

$1 / \tau_{\mathrm{B}(\mathrm{S})}=1 / \tau_{\mathrm{B}(\mathrm{S})}^{\mathrm{Rad}}+1 / \tau_{\mathrm{B}(\mathrm{S})}^{\mathrm{NR}}$.

At the same time, bearing in mind that the radiative recombination is low and does not contribute to the lattice heating, the first term can be neglected. As a result, $\tau_{\mathrm{B}}=\tau_{\mathrm{B}}^{\mathrm{NR}}$ and $\tau_{\mathrm{S}}=\tau_{\mathrm{S}}^{\mathrm{NR}}$. Hence, under the PLI conditions, the NEC lifetime in the CdTe bulk is mainly governed by the Auger recombination, whereas the NEC lifetime at the CdTe surface by the surface recombination rate $S$.

In our calculations, we used the typical parameters of the detector high-resistance $\gamma$-CdTe (Acrorad Co. Ltd) (see Table) [2-5]. At the nanosecond laser irradiation, the measured NEC lifetime amounts to $3 \times 10^{-8} \mathrm{~s}[5]$. The parameter $\eta_{Q}$ demonstrates the 
Physical parameters of CdTe

\begin{tabular}{|l|c|}
\hline \multicolumn{1}{|c|}{ Parameter } & Value \\
\hline Density $\rho_{0}, \mathrm{~kg} / \mathrm{m}^{3}$ & 5860 \\
Melting temperature, ${ }^{\circ} \mathrm{C}$ & 1092 \\
Specific heat $\left.c_{P}, \mathrm{~J} / \mathrm{kg} \cdot \mathrm{K}\right)$ & 209 \\
Temperature conductivity $k, \mathrm{~m}^{2} / \mathrm{s}$ & $7.1(5.8) \times 10^{-6}[22]$ \\
Temperature dependence of density, $\mathrm{kg} / \mathrm{m}^{3}$ & $5887-0.1165 \times T[21]$ \\
Temperature dependence of specific heat $\left.c_{\mathrm{P}}, \mathrm{J} / \mathrm{kg} \cdot \mathrm{K}\right)$ & $205+3.6 \times 10^{-2} \times T[16,17,22]$ \\
Temperature dependence of temperature conductivity $k, \mathrm{~m}^{2} / \mathrm{s}$ & $2.16 \times 10^{-3} / T[22]$ \\
Temperature dependence of heat conductivity, $\mathrm{J} /(\mathrm{m} \cdot \mathrm{s} \cdot \mathrm{K})$ & $1507 / T[16,17,22]$ \\
Optical and electronic parameters of CdTe at $\lambda=694 \mathrm{~nm}(\mathrm{ruby}$ laser $)$ & $0.28[20,24]$ \\
Reflectance $R$ & $3 \times 10^{6}[17,24]$ \\
Absorption coefficient $\alpha, \mathrm{m}{ }^{-1}$ & $(300 \mathrm{~K}), 5.7 \times 10^{-4}(1000 \mathrm{~K})$ \\
Coefficient of NEC ambipolar diffusion $D, \mathrm{~m}^{2} / \mathrm{s}$ & $(0.5-1) \times 10^{-9}[5,23]$ \\
NEC bulk lifetime $\tau_{\mathrm{B}}($ for $p$-CdTe $), \mathrm{s}$ & $1.7 \times 10^{-3}[5,23]$ \\
NEC surface lifetime $\tau_{\mathrm{S}}, \mathrm{s}$ & $122,23]$ \\
Constant of Auger recombination $\gamma_{\mathrm{Aug}}, \mathrm{cm}^{6} / \mathrm{s}$ & $3.9 \times 10^{3}-10^{5}[1,5,7,23]$ \\
Rate of surface nonradiative recombination $S, \mathrm{~m} / \mathrm{s}$ & $0.3-0.78$ \\
Dimensionless parameter $\eta_{Q}$ & 1.5 \\
Recombination energy $E_{\mathrm{R}}, \mathrm{eV}$ & $1000-1100(300 \mathrm{~K})[1,22]$ \\
Electron mobility $\mu_{\mathrm{n}}, \mathrm{cm}{ }^{2} /(\mathrm{V} \cdot \mathrm{s})$ & $80-100(300 \mathrm{~K})[1,22]$ \\
Hole mobility $\mu_{\mathrm{p}}, \mathrm{cm}{ }^{2} /(\mathrm{V} \cdot \mathrm{s})$ & $(0.4-2) \times 10^{-6}[23]$ \\
NEC diffusion depth $L_{\mathrm{D}}($ for $p$-CdTe $), \mathrm{m}$ & \\
\hline
\end{tabular}

ratio between the energy of photons that was immediately thermalized at the absorption depth $1 / \alpha$ and the energy of photons that was transferred to NECs and released at the recombination at the NEC diffusion depth $L_{\mathrm{D}}$ (the recombination energy). The parameter $\eta_{Q}$ is a little uncertain for CdTe under PLI (see Table). However, the calculations showed that, when it changes from 0.3 to 0.78 , the magnitude of $I_{\mathrm{th}}$ changes by a factor of 1.08 . As a rule, $\eta_{Q}$ is close to 1 for some semiconductors ( $\mathrm{InSb}$, $\mathrm{Si})[18]$.

Figure 1 demonstrates the results of calculations for the CdTe melting threshold under PLI within a wavelength interval of 300-800 $\mathrm{nm}$ and, for descriptive reasons, the literature data for $R(\lambda)$ and $\alpha(\lambda)$ on the logarithmic scale. The calculation was performed, by using formulas (1) and (2) and taking the data from Table into account. At $\lambda>800 \mathrm{~nm}-$ especially, in the interval of CdTe transparency $(\lambda>850 \mathrm{~nm})-$ two-photon absorption and, accordingly, the defect and doping impurity concentrations, which strongly affect $I_{\mathrm{th}}$, have to be taken into account. Usually, the coefficient of two-photon absorption in $\mathrm{CdTe} \beta=$ $0.1 \div 0.2 \mathrm{~cm} / \mathrm{MW}($ at $\lambda=1.064 \mu \mathrm{m})$.
One can see that, when $\lambda$ changes from 380 to $800 \mathrm{~nm}$, the reflectance $R$ changes from 0.4 to 0.29 , i.e. it increases by a factor of 1.38. At the same time, the absorption coefficient $\alpha$ changes from $4.4 \times 10^{5}$ to $2.1 \times 10^{4} \mathrm{~cm}^{-1}$, i.e. it decreases by more than an order of magnitude. It is evident that, if only the reflectance $R$ decreases, the melting threshold $I_{\text {th }}$ also decreases [formula (1)]; but if only $\alpha$ decreases, $I_{\text {th }}$ increases, because a larger volume in the near-surface CdTe layer is heated up. Therefore, the dependence $\alpha(\lambda)$ is responsible for the behavior of the dependence $I_{\mathrm{th}}(\lambda)$. In an interval of 300$420 \mathrm{~nm}$, the curve $R(\lambda)$ has two peaks, where the variation of $R$ amounts to $5 \%$. The parameter $a$ also has two small peaks in this interval. They are associated with the electron transition into minimum $L$ in the conduction band $\left(L_{4.5}-L_{6}\right.$ and $L_{6}-L_{6}$ transitions). Such a characteristic behavior of the curves $R(\lambda)$ and $\alpha(\lambda)$ in the indicated interval reveals itself in the dependence $I_{\mathrm{th}}(\lambda)$, where a maximum and a minimum are observed (Fig. 1). Hence, when the wavelength of a pulsed laser radiation changes from 300 to $800 \mathrm{~nm}$, the melting threshold grows from 2.6 to $4.75 \mathrm{MW} / \mathrm{cm}^{2}$, i.e. it almost doubles. 
Below $\lambda=300 \mathrm{~nm}$, the absorption coefficient in CdTe is very high, and light is absorbed at a depth of about $10 \mathrm{~nm}$. For example, for an excimer $\mathrm{KrF}$ laser $\left(\lambda=248 \mathrm{~nm}, \tau_{\mathrm{p}}=20 \mathrm{~ns}, \alpha=1.1 \times 10^{6} \mathrm{~cm}^{-1}\right)$, the melting threshold $I_{\mathrm{th}}=2.5 \mathrm{MW} / \mathrm{cm}^{2}[3,4,16]$. On the other hand, according to our calculations, $I_{\text {th }}=$ $=2.71 \mathrm{MW} / \mathrm{cm}^{2}$, which is quite a reasonable value, because the reflectance $R$ has rather a high value of 0.46 at $\lambda=248 \mathrm{~nm}[22]$.

Also important is the dependence of the melting threshold on the pulse duration $\tau_{\mathrm{p}}$. This dependence is depicted in Fig. 2. One can see that the power density of the melting threshold falls down rather drastically with the growth of $\tau_{\mathrm{p}}$ [in accordance with formulas (1) and (2)]. The corresponding depth and, accordingly, volume of the heated-up layer increase at that. If the pulse duration becomes smaller, the rate of energy delivery becomes higher, and the processes of NEC thermalization and heat transfer into deeper layers owing to the heat conductivity become slower.

The dependence in Fig. 2 provides information about the melting threshold change at the variation of the pulse duration from 7 to $120 \mathrm{~ns}$, because typical lasers operating in the $Q$-switching mode have a pulse duration of $7,15,20,80$, or $120 \mathrm{~ns}$. The plot in Fig. 2, $b$ demonstrates the dependence concerned in a wide $\tau_{\mathrm{p}}$-interval from $2 \mathrm{~ns}$ to $1.2 \mu \mathrm{s}$ on the log-log scale. The growth of $\tau_{\mathrm{p}}$ by six orders of magnitude stimulates the decrease of $I_{\mathrm{th}}$ by three orders of magnitude from $20 \mathrm{MW} / \mathrm{cm}^{2}$ to $10 \mathrm{~kW} / \mathrm{cm}^{2}$.

At $\tau_{\mathrm{p}}=80 \mathrm{~nm}$ and $\lambda=694 \mathrm{~nm}$, the theoretical value of $I_{\mathrm{th}}$ for CdTe equals $I_{\mathrm{th}}=1.9 \mathrm{MW} / \mathrm{cm}^{2}$ (Fig. 2, a). The corresponding experimental value equals $1.5 \mathrm{MW} / \mathrm{cm}^{2}[2]$, i.e. an agreement takes place. In work [17], the theoretical value for $I_{\mathrm{th}}$ at $\tau_{\mathrm{p}}=100 \mathrm{~ns}$ equals $0.6 \mathrm{MW} / \mathrm{cm}^{2}\left(60 \mathrm{~kJ} / \mathrm{cm}^{2}\right)$; the calculations take into account the cadmium evaporation, owing to which $\mathrm{CdTe}$ begins to melt at a certain depth from its surface. Furthermore, according to our calculations, the CdTe melting threshold equals $9.08 \mathrm{~kW} / \mathrm{cm}^{2}$ at the ruby laser pulse duration $\tau_{\mathrm{p}}=1.2 \mathrm{~ms}$. This value is close enough to a value of $4.2 \mathrm{~kW} / \mathrm{cm}^{2}\left(5 \mathrm{~J} / \mathrm{cm}^{2}\right)$, which was obtained theoretically and experimentally in work [25].

One can see that, within the pulse duration interval from 5 to $100 \mathrm{~ns}, I_{\text {th }}$ changes from 10.5 to $1.46 \mathrm{MW} / \mathrm{cm}^{2}$, i.e. by a factor of seven. At $\tau_{\mathrm{p}}=$ $=20 \mathrm{~ns}$, we have $I_{\mathrm{th}}=4.17 \mathrm{MW} / \mathrm{cm}^{2}$. When the pulse duration changes from 15 to $25 \mathrm{~ns}$, the value of
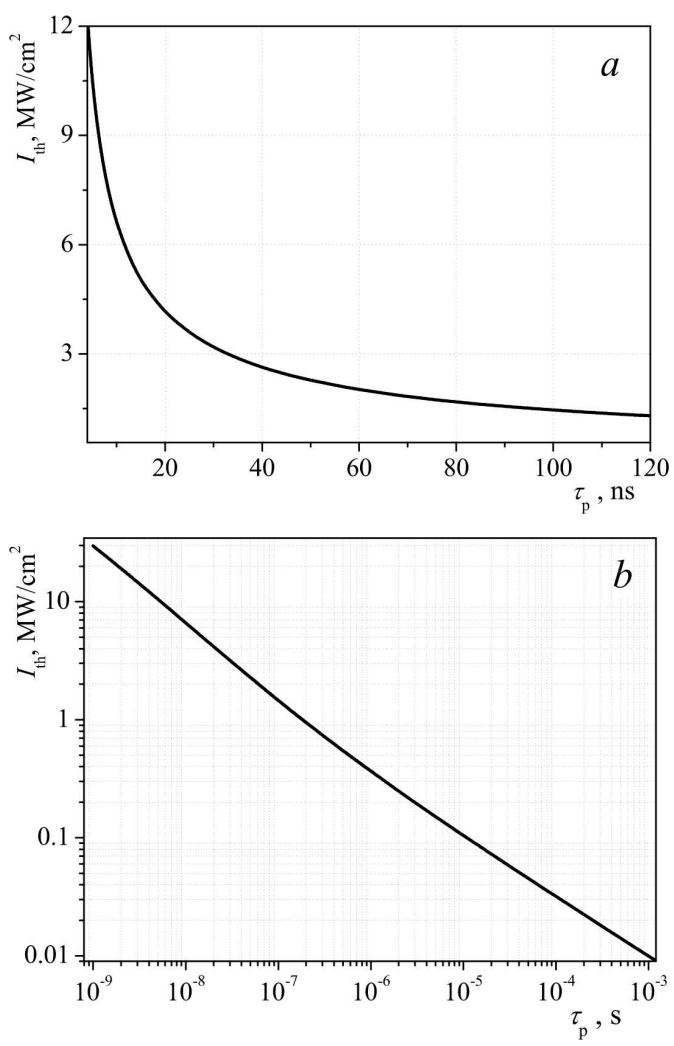

Fig. 2. Dependence of the CdTe melting threshold pulse duration $\tau_{\mathrm{p}}: \tau_{\mathrm{p}}<120 \mathrm{~ns}(a)$ and $\tau_{\mathrm{p}}<1.2 \mathrm{~ms}(b) . \lambda=694 \mathrm{~nm}$

$I_{\text {th }}$ changes from 5.05 to $3.6 \mathrm{MW} / \mathrm{cm}^{2}$. This means that the variation of the pulse duration from 15 to $25 \mathrm{~ns}$ is accompanied by the relative change of the power density $\Delta I_{\mathrm{th}} / I_{\mathrm{th}}(20 \mathrm{~ns})=(5.05-3.6) / 4.17=$ $=0.35$. This fact is important to be taken into consideration, while treating semiconductors, when $\tau_{\mathrm{p}}$ can change a little during a long time interval of the laser application.

Note that, if the pulse duration becomes shorter than $1 \mathrm{~ns}$, the electric field strength grows strongly, so that such processes as ablation, ionization, laserinduced breakdown of vapor over the surface, and so forth start to play a significant role.

The calculation of the CdTe melting threshold by formulas (1) and (2) for a ruby laser with $\tau_{\mathrm{p}}=20 \mathrm{~ns}$ gave the values $I_{\mathrm{th}}=4.17 \mathrm{MW} / \mathrm{cm}^{2}$ (Fig. 3) and $L_{\mathrm{H}}=0.33 \mu \mathrm{m}$. One can see that the dependence $T(I)$ is nonlinear due to the strong temperature dependences of the thermal parameters $c_{\mathrm{P}}, \chi$, and $\rho$, which change by tens of percent, when $T$ grows from $0{ }^{\circ} \mathrm{C}$ to $1092{ }^{\circ} \mathrm{C}$ (Table). As a result, the value of $I_{\text {th }}$ 


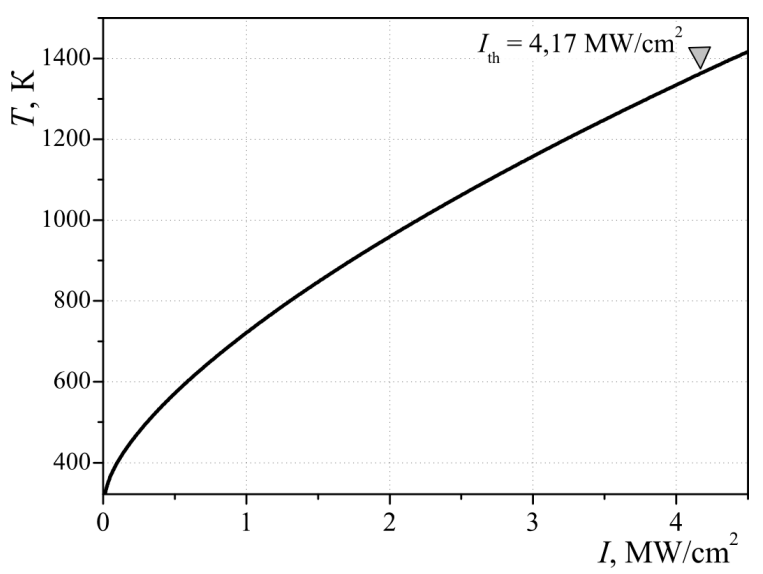

Fig. 3. Dependence of the CdTe surface temperature on the pulse power density of a ruby laser at $\tau_{\mathrm{p}}=20 \mathrm{~ns}$

becomes strongly dependent on $T$. The evaluation of $I_{\text {th }}$ according to expression (1), at $L_{\mathrm{H}}=\sqrt{k \tau_{\mathrm{p}}}$, and assuming the thermal parameters to be independent of $T$ gives rise to a value of $6 \mathrm{MW} / \mathrm{cm}^{2}$.

Electronic and optical parameters of the surface will be different a little, depending on the specific kind of a surface treatment: cleavage, polishing, etching, annealing in a definite atmosphere, and so on [7]. The change of NEC parameters $\left(\tau_{\mathrm{B}}, S, L_{\mathrm{D}}\right)$, provided the definite kind of a surface treatment, was found to affect the magnitude of $I_{\mathrm{th}}$ as follows. The growth of the surface recombination rate $S$ from $10^{3}$ to $10^{5} \mathrm{~m} / \mathrm{s}$ and the corresponding change of the surface recombination time $\tau_{\mathrm{S}}^{\mathrm{NR}}$ result in the variation of $I_{\mathrm{th}}$ by $5 \%$. The growth of $L_{\mathrm{D}}$ from 0.4 to $2 \mu \mathrm{m}$ stimulates the increase of $I_{\text {th }}$ by $19 \%$. This is so, because, in our case, the term $\chi_{\mathrm{S}}^{\mathrm{NR}}$ [Eq. (5)] in the integrand-this term includes the parameters of the surface recombination-is smaller than the term $\chi_{\mathrm{T}}$ [Eq. (3)], and $\tau_{\mathrm{B}}^{\mathrm{NR}}$ is larger than $\tau_{\mathrm{S}}^{\mathrm{NR}}$ by an order of magnitude.

Therefore, a certain mismatch in the literature for the values of CdTe melting threshold under the nanosecond laser irradiation can be associated with the application of different kinds of a surface treatment and different (doped/undoped) CdTe crystals, because $I_{\text {th }}$ demonstrates its dependence on the NEC parameters.

\section{Conclusions}

The CdTe melting threshold is calculated as a function of the pulsed laser irradiation wavelength $\lambda$ and the pulse duration $\tau_{\mathrm{p}}$. It is shown that the

\section{4}

melting threshold $I_{\mathrm{th}}$ at $\tau_{\mathrm{p}}=20 \mathrm{~ns}$ changes from 2.6 to $4.75 \mathrm{MW} / \mathrm{cm}^{2}$, when $\lambda$ grows from 300 to $800 \mathrm{~nm}$. Again, $I_{\text {th }}$ changes from 10.5 to $1.46 \mathrm{MW} / \mathrm{cm}^{2}$, when the duration of a ruby laser pulse increases from 5 to 100 ns. The theoretically calculated values agree well with literature experimental data.

It is shown that the variation of the ruby-laser pulse duration within a typical interval of $20 \pm 5 \mathrm{~ns}$ induces the relative change $\Delta I_{\mathrm{th}} / I_{\mathrm{th}}=35 \%$ of the melting threshold. This fact has to be taken into account when applying PLI of the CdTe surface in various technological tasks. It is found that the increase of the surface recombination rate $S$ from $10^{3}$ to $10^{5} \mathrm{~m} / \mathrm{s}$ changes the melting threshold $I_{\text {th }}$ by $5 \%$. The increase of the NEC diffusion depth $L_{\mathrm{D}}$ from 0.4 to $2 \mu \mathrm{m}$ under the ruby-laser irradiation changes $I_{\text {th }}$ by $19 \%$. Finally, the modification of $\eta_{Q}$ from 0.3 to 0.78 changes $I_{\text {th }}$ by $8 \%$. Hence, the variation in the NEC parameters can affect the CdTe melting threshold by at least $30 \%$.

Our researches were sponsored by the State Fund for Fundamental Researches of Ukraine [projects F64/16-2016 (state registration No.0116U003954) and F68/54-2016 (state registration No.0116U005451)] and, partially, by the NATO Science for Peace and Security Programme (project SENERA, SfP-984705).

1. D.V. Korbutyak, S.V. Melnychuk, E.V. Korbut, M.M. Borysyuk, Cadmium Telluride: Impurity-Defect States and Detector Properties (Ivan Fedorov, 2000) (in Ukrainian).

2. V.A. Gnatyuk, T. Aoki, Y. Hatanaka, O.I. Vlasenko. Metal-semiconductor interfaces in CdTe crystals and modification of their properties by laser pulses. Appl. Surf. Sci. 244, 528 (2005) [DOI: 10.1016/j.apsusc.2004.10.113].

3. V.A. Gnatyuk, T. Aoki, Y. Nakanishi, Y. Hatanaka. Surface state of CdTe crystals irradiated by $\mathrm{KrF}$ excimer laser pulses near the melting threshold. Surf. Sci. 542, 142 (2003) [DOI: 10.1016/S0039-6028(03)00987-7].

4. V.A. Gnatyuk, T. Aoki, O.S. Gorodnychenko, Y. Hatanaka. Solid-liquid phase transitions in CdTe crystals under pulsed laser irradiation. Appl. Phys. Lett. 83, 3704 (2003) [DOI: 10.1063/1.1625777].

5. L.A. Kosyachenko, T. Aoki, C.P. Lambropoulos, V.A. Gnatyuk, S.V. Melnychuk, V.M. Sklyarchuk, E.V. Grushko, O.L. Maslyanchuk, O.V. Sklyarchuk. Optimal width of barrier region in $\mathrm{X} / \gamma$-ray Schottky diode detectors based on CdTe and CdZnTe. J. Appl. Phys. 113, 054504 (2013) [DOI: 10.1063/1.4790358].

6. A. Baidullaeva, A.I. Vlasenko, L.F. Kuzan, O.S. Litvin, P.E. Mozol'. Formation of nanoscale structures on the sur- 
face of $p$-CdTe crystals under the action of a single pulse of ruby laser. Fiz. Tekh. Poluprovodn. 39, 1064 (2005) (in Russian).

7. V.P. Makhnii, I.I. German, E.I. Chernykh. Influence of treatment on the surface parameters of singlecrystalline cadmium telluride substrates. Poverkhn. Rentgen. Sinkhrotron. Neitron. Issled. N 6, 65 (2013) (in Russian).

8. L.A. Golovan', P.K. Kashkarov, V.M. Lakeenkov et al. Rutherford backscattering study of laser-induced defect formation in CdTe crystals. Fiz. Tverd. Tela 40, 209 (1998) (in Russian).

9. L.A. Golovan', P.K. Kashkarov, V.Yu. Timoshenko. Laserinduced melting and defect formation in cadmium telluride. Laser Phys. 6, 925 (1996).

10. A. Baidulaeva, V.P. Veleshchuk, A.I. Vlasenko, B.K. Dauletmuratov, O.V. Lyashenko, P.E. Mozol'. Effect of melting on the acoustic response of CdTe and GaAs compounds under pulsed laser irradiation. Fiz. Tekh. Poluprovodn. 42, 286 (2008) (in Russian).

11. R.O. Bell, M. Toulemonde, P. Siffert. Calculated temperature distribution during laser annealing in silicon and cadmium telluride. J. Appl. Phys. 19, 313 (1979) [DOI: 10.1007/BF00900475].

12. N.G. Blamires, D.H.J. Totterdel. Orientation dependent surface damage observed in laser irradiated cadmium telluride. J. Phys. D 16, 2361 (1983) [DOI: 10.1088/00223727/16/12/014].

13. I.L. Shul'pina, N.K. Zelenina, O.A. Matveev. Effects of pulsed laser radiation on the real structure of CdTe crystals. Fiz. Tverd. Tela 40, 68 (1998) (in Russian).

14. I.L. Shul'pina, N.K. Zelenina, O.A. Matveev. Thermal effects of pulsed laser radiation on the real structure of CdTe crystals. Fiz. Tverd. Tela 42, 548 (2000) (in Russian).

15. I.L. Shul'pina, V.V. Ratnikov, O.A. Matveev. X-ray diffraction study of changes in the real structure of CdTe single crystals after laser irradiation. Fiz. Tverd. Tela 43, 559 (2002) (in Russian).

16. S.P. Zhvavyi, G.L. Zykov. Numerical simulation of the dynamics of phase transitions in CdTe induced by nanosecond excimer laser radiation. Fiz. Tekh. Poluprovodn. 40, 652 (2006) (in Russian).

17. A.A. Kovalev, S.P. Zhvavyi, G.L. Zykov. Dynamics of laserinduced phase transitions in cadmium telluride. Fiz. Tekh. Poluprovodn. 39, 1345 (2005) (in Russian).

18. J.R. Meyer, M.R. Kruer, F.J. Bartoli. Optical heating in semiconductors: Laser damage in $\mathrm{Ge}, \mathrm{Si}, \mathrm{InSb}$, and GaAs. J. Appl. Phys. 51, 5513 (1980) [DOI: 10.1063/1.327469].

19. V.V. Apollonov, A.M. Prokhorov, V.Yu. Khomich, S.A. Chetkin. Thermoelastic action of pulse-periodic laser radiation on the surface of a solid. Sov. J.
Quant. Electron. 12, 188 (1982) [DOI: 10.1070/ QE1982v012n02ABEH005473].

20. E.I. Gatskevich, G.D. Ivlev, P. Přikryl, R. Černý, V. Cháb, O. Cibulka. Pulsed laser-induced phase transformations in CdTe single crystals. Appl. Surf. Sci. 248, 259 (2005) [DOI: 10.1016/j.apsusc.2005.03.045].

21. V.M. Glazov, L.M. Pavlova. Temperature dependences of the density and the character of interaction between particles in molten zinc and cadmium tellurides. Zh. Fiz. Khim. 75, 1735 (2001) (in Russian).

22. O. Madelung. Semiconductors: Data Handbook (Springer, 2004).

23. R. Triboulet, P. Siffert. CdTe and Related Compounds; Physics, Defects, Hetero- and Nano-Structures, Crystal Growth, Surfaces and Applications (Elsevier, 2010).

24. V.I. Gavrilenko, A.M. Grekhov, D.V. Korbutyak, V.G. Litovchenko. Optical Properties of Semiconductors (Naukova Dumka, 1987) (in Russian).

25. O.V. Galochkin, V.M. Zhyharevych, G.I. Rarenko, V.M. Strebezhev, Ya.D. Zakharuk, S.G. Dremlyuzhenko. Influence of powerful millisecond laser radiation on the depth of melted layer in $\mathrm{CdTe}$ and $\mathrm{Cd}_{0.8} \mathrm{Mn}_{0.2} \mathrm{Te}$ crystals. Fiz. Khim. Tverd. Tila 13, 224 (2012) (in Ukrainian).

Received 12.10.16.

Translated from Ukrainian by O.I. Voitenko

В.П. Велещук, О.І. Власенко,

3.К. Власенко, В.А. Гнатюк, С.М. Левицъкий

ЗАЛЕЖНІСТЬ ПОРОГА ПЛАВЛЕННЯ СdТе ВІД ТРИВАЛОСТІ ІМПУЛЬСУ ТА ДОВЖКИИ ХВИЛІ ВИПРОМІНЮВАННЯ ЛАЗЕРА І ПАРАМЕТРІВ НЕРІВНОВАЖНИХ НОСІЇВ ЗАРЯДУ

$\mathrm{P}$ е $з$ ю м е

Розраховано поріг плавлення СdTе в залежності від довжини хвилі випромінювання $I_{\mathrm{th}}(\lambda)$ та тривалості лазерного імпульсу $I_{\mathrm{th}}\left(\tau_{\mathrm{p}}\right)$ з урахуванням параметрів ННЗ. При наносекундному лазерному опроміненні CdTe в області фундаментального поглинання враховано три компоненти енергії, що виділяється при термалізації збуджених носіїв - відразу після збудження (1), при безвипромінювальній об'ємній (2) та безвипромінювальній поверхневій (3) рекомбінації, які в сукупності визначають глибину проникнення тепла у кристал і відповідно поріг плавлення. Показано, що поріг плавлення змінюється від 2,6 до 4,75 MBт/см ${ }^{2}$ при зростанні $\lambda$ від 300 нм до 800 нм при $\tau_{\mathrm{p}}=20$ нс. Виявлено, що зміна параметрів ННЗ - швидкості поверхневої рекомбінації, часу життя, глибини дифузії може змінити поріг плавлення CdTe принаймні на 30 відсотків. 